\title{
Icelandic Birch Polyploids-The Case of a Perfect Fit in Genome Size
}

\author{
K. Anamthawat-Jónsson, ${ }^{1}$ Æ. Th. Thórsson, ${ }^{1}$ E. M. Temsch, ${ }^{2}$ and J. Greilhuber ${ }^{2}$ \\ ${ }^{1}$ Department of Life and Environmental Sciences, School of Engineering and Sciences, University of Iceland, \\ Askja-Sturlugata 7, Reykjavik IS-101, Iceland \\ ${ }^{2}$ Department of Systematic and Evolutionary Botany, University of Vienna, Rennweg 14, 1030 Vienna, Austria
}

Correspondence should be addressed to K. Anamthawat-Jónsson, kesara@hi.is

Received 31 January 2010; Accepted 22 April 2010

Academic Editor: Ilia Judith Leitch

Copyright $(\odot 2010 \mathrm{~K}$. Anamthawat-Jónsson et al. This is an open access article distributed under the Creative Commons Attribution License, which permits unrestricted use, distribution, and reproduction in any medium, provided the original work is properly cited.

\begin{abstract}
Two birch species coexist in Iceland, dwarf birch Betula nana and tree birch B. pubescens. Both species are variable morphologically, which has been shown to be due to introgressive hybridization via interspecific hybrids. The aim of this study was to examine if the introgression could be related to genome size. We characterized 42 plants from Bifröst woodland morphologically and cytogenetically. The population consisted of diploid B. nana (38\%), tetraploid B. pubescens (55\%), and triploid hybrids (7\%). Genome size was measured from 12 plants, using Feulgen DNA image densitometry (FDM) on spring leaf buds and flow cytometry (FCM) with dormant winter twigs. The use of winter twigs for FCM is novel. The average 1C-values for diploid, triploid, and tetraploid plants were 448, 666, and $882 \mathrm{Mbp}$, respectively. Monoploid genome sizes were found to be statistically constant among ploidy levels. This stability is in contrast to the different taxonomic positions of the di- and tetraploids and also contrasts with the frequent occurrence of genome downsizing in polyploids.
\end{abstract}

\section{Introduction}

Two species of Betula L. coexist in Iceland [1]: the diploid dwarf birch $B$. nana $\mathrm{L}$. and the tetraploid tree birch $B$. pubescens Ehrh. Betula nana, a circumpolar species [2], grows up to one metre in height with procumbent, widespreading stems and a strong branching habit. Betula pubescens is a European species [3], represented by the subspecies pubescens Ehrh., which may grow up to $25 \mathrm{~m}$ tall with single or many stems (monocormic or polycormic type), and subspecies tortuosa (Ledeb.) Nyman is a shrub or low tree found in the mountain regions of northern Europe and is therefore called "mountain birch". Betula pubescens in Iceland has sometimes also been referred to as mountain birch due to its low stature and scrub-like growth form [4]. Elkington [5] compared birch from Iceland and Scotland and suggested that the morphological variability and the shrub-like appearance of Icelandic birch were due to genetic introgression from $B$. nana into $B$. pubescens via triploid interspecific hybrids. This was confirmed by both crossing experiments and population-based studies $[1,6]$.
Furthermore, these studies revealed that the introgression occurred in both directions, that is, not only from the diploid to the tetraploid species but also from the tetraploid to the diploid birch species, resulting in a high degree of variation in both B. nana and B. pubescens.

Due to this bidirectional introgression between the two Betula species, taxonomic delineation in Icelandic birch has been difficult, especially with the tree birch species $B$. pubescens. Morphological variation in birch plants from natural woodlands throughout Iceland was examined using both qualitative species-specific botanical characters and quantitative morphological variables [7]. The study revealed that Icelandic birch populations consisted mostly of introgressant types. Whereas about $11 \%$ of all plants examined were "morphologically pure" B. nana, not a single plant had all of the species-specific characters of $B$. pubescens. Indeed only $1 \%$ of the plants examined had more than $80 \%$ of the B. pubescens characters. But when the plants were sorted according to chromosome number, which was determined by direct chromosome counting of mitotic metaphases, three groups of birch emerged: diploid $(2 n=28)$, triploid 
TABle 1: Plant materials, ploidy determination, morphology evaluation, and genome size measurements (C- and $\mathrm{Cx}$-values in $\mathrm{Mbp})$ from FDM and FCM.

\begin{tabular}{|c|c|c|c|c|c|c|c|}
\hline \multirow{2}{*}{ Plant identity number } & \multirow{2}{*}{ Ploidy by karyotype } & \multirow{2}{*}{ DNA Ploidy } & \multirow{2}{*}{ Morphology index } & \multicolumn{2}{|c|}{$1 \mathrm{Cx}$-values } & \multicolumn{2}{|c|}{ 2C-values } \\
\hline & & & & FDM-buds & FCM-twigs & FDM-buds & FCM-twigs \\
\hline $\mathrm{Bn}-1$ & - & $2 \mathrm{x}$ & - & & 453.4 & & 906.8 \\
\hline $\mathrm{Bn}-2$ & - & $2 \mathrm{x}$ & - & & 461.7 & & 923.4 \\
\hline 44 & $2 \mathrm{x}$ & $2 \mathrm{x}$ & 1 & 441.2 & & 882.4 & \\
\hline 46 & $2 \mathrm{x}$ & $2 \mathrm{x}$ & 3 & 431.8 & & 863.6 & \\
\hline 51 & $2 \mathrm{x}$ & $2 \mathrm{x}$ & 1 & 451.1 & & 902.2 & \\
\hline 72 & $3 x$ & $3 x$ & 4 & & 443.4 & & 1330.2 \\
\hline 81 & $3 x$ & $3 \mathrm{x}$ & 4 & 447.2 & 441.7 & 1341.6 & 1325.1 \\
\hline 71 & $4 \mathrm{x}$ & $4 \mathrm{x}$ & 6 & 445.4 & 439.3 & 1781.4 & 1757.2 \\
\hline 83 & $4 \mathrm{x}$ & $4 \mathrm{x}$ & 7 & 433.7 & 453.5 & 1734.8 & 1814.0 \\
\hline 85 & $4 \mathrm{x}$ & $4 \mathrm{x}$ & 8 & & 430.2 & & 1720.8 \\
\hline 92 & $4 \mathrm{x}$ & $4 \mathrm{x}$ & 10 & 439.7 & 438.4 & 1758.8 & 1753.6 \\
\hline 95 & $4 \mathrm{x}$ & $4 x$ & 9 & & 448.2 & & 1792.8 \\
\hline
\end{tabular}

$(2 n=42)$, and tetraploid $(2 n=56)$. The diploid $(2 n=28)$ group consisted mainly of $B$. nana and $B$. nana-like plants, although some diploid plants showed intermediate "hybrid" morphology. The tetraploid group consisted of B. pubescenslike plants and a significant proportion of plants that had intermediate morphology. The triploid group (about 10\% of all plants examined) showed no "typical" morphology, although there was a trend towards greater similarity to B. nana. The multivariate data analysis of morphological variables was able to separate diploid B. nana from tetraploid B. pubescens most of the time, but triploid hybrids were difficult to predict;-only half of them were assigned correctly.

The three genome groups in Icelandic birch were distinguishable statistically but their morphological variation overlapped in most of the distribution, implying bidirectional introgression $[7,8]$. The question is whether this introgressive hybridization has affected genome size and if so, to what extent. There might be large-scale genomic recombination and shuffling following the hybridization and back-crossing, leading to genome size changes and significant variation within and between genome groups. Genome downsizing has been shown to be common in angiosperms [9], whereby genome size does not increase in direct proportion with ploidy. Genome size expansion due to transposition has also been documented, but there seems to be a large variation in the nature and extent of opposing forces to genome obesity $[10,11]$, making the direction of genome size change in a given species difficult to predict. On the other hand, there may be no deviation at all in genome size proportional to ploidy if there is sufficient (strong) selection pressure against genome-wide (neutral) introgression, especially in hybrid zones. For the hybrid zones to be stable, they require some form of divergent selection (intrinsic and/or extrinsic) to maintain differentiation (species integrity) despite extensive gene flow. Divergent selection has been suggested to contribute to heterogeneous genomic divergence and ecological speciation [12] and to play an important role in hybrid zone maintenance [13]. Our morphological $[7,8]$ and molecular [14] studies have supported the suggestion that Iceland is a birch hybrid zone, harbouring genetic variation which may be advantageous in subarctic regions.

The aim of the present study was therefore to get the first set of genome size data on Icelandic birch, including samples from all three ploidy groups (diploid, triploid, and tetraploid) from one of the most extensive birch woodlands in Iceland. Two approaches were used to measure genome size in these samples: (A) the Feulgen DNA image densitometry (FDM) method for squashed preparations of meristematic cells in newly bursting shoot buds and (B) the flow cytometry (FCM) method for cells from winterdormant twigs. The genome size data generated in this study will undoubtedly contribute to the understanding of the process and mechanism of introgressive hybridization in Icelandic birch.

\section{Materials and Methods}

2.1. Plant Materials. Plant materials in this study came from the Bifröst woodland $\left(64.76^{\circ} \mathrm{N} / 21.59^{\circ} \mathrm{W}, 62\right.$ m.a.s.l., $11^{\circ} \mathrm{C}$ mean July temperature), by Lake Hredavatn in Borgarnes district, West Iceland. This is part of the largest continuous woodland area still in existence today. In this woodland, like most other woodlands in Iceland, both $B$. nana and $B$. pubescens grow most often side by side, although $B$. nana tends to be more dominant on wet ground, whereas $B$. pubescens occupies drier land. A total of 42 plants were selected within an area of about one $\mathrm{km}^{2}$ and with a distance of at least $20 \mathrm{~m}$ between plants. The plants were marked in the field to enable a long-term study, whereby samples could be collected from the same plants in different visits over a number of years.

2.2. Morphological and Cytogenetic Characterization. For the morphological analysis, 30 leaves were collected from each plant. These were late leaves from long shoots, normally from the third to fifth positions from the shoot tip. Discrete, species-specific morphological characters were used to 
determine the morphological variation of $B$. nana and $B$. pubescens. Eight characters including growth form, growth habit, and characteristics of leaf shape were examined qualitatively and scored as described previously [8], whereby each character was given two or three possible scores from zero (B. nana) to one or two (B. pubescens). Scores for leaf characters of each plant were assigned using average values from 30 leaves that had been pressed, sealed in plastic, and scanned. The scores of all characters were then combined for each plant into a single value, called a morphology index. This was assigned to place $B$. nana at the lowest ranks and $B$. pubescens at the highest.

The same sets of leaves were analysed quantitatively. The quantitative analysis of leaf characters was performed for nine variables as in [7], using the leaf morphology analysis program WinFolia (Regent Instruments, Quebec, Canada). The measured characters were analysed using the multivariate analysis of variance (MANOVA) and the linear discriminant analysis (LDA) described in [15].

Samples of bursting leaf buds in early spring (MayJune) were collected in the field for chromosome analysis. The chromosome number of each plant was determined by direct chromosome counting, from metaphases prepared from shoot-tip meristems using the protoplast dropping method of Anamthawat-Jónsson [16]. The chromosome preparations were stained with the fluorescent dye DAPI (4, 6-diaminophenylindole) and visualized under a Nikon epifluorescence microscope (Eclipse 800) using 1000x magnification. The images were captured with a Nikon digital camera (DXM 1200F) using 12.5 million pixels. Chromosomes were counted from 10-20 metaphases from each plant.

\subsection{Genome Size Determination Using Feulgen DNA Image} Densitometry. Seven samples (individuals) of birch from the Bifröst woodland (Table 1) were collected in the field in May 2007 and were airmailed as twigs with early sprouting buds under a moist condition from Reykjavik to Vienna. Buds were detached and flooded with $4 \%$ phosphatebuffered formaldehyde ( $\mathrm{pH} 7)$ in embryo cups and cut open. Bud meristems and leaf primordia were dissected out and fixed for $1.5 \mathrm{~h}$ at $20^{\circ} \mathrm{C}$ synchronously with embryonic roots and shoots from dry seeds of Pisum sativum "Kleine Rheinländerin" for internal standardization of the Feulgen reaction. Extensive washes with acetic-methanol $(1: 3)$ were performed, to remove formaldehyde from the tissue. The material was then rinsed extensively and finally stored in $96 \%$ ethanol at $-20^{\circ} \mathrm{C}$ until use.

The Feulgen reaction was done as described in [17], that is, hydrolysis in $5 \mathrm{~N} \mathrm{HCl}$ for $90 \mathrm{~min}$. at $20^{\circ} \mathrm{C}$, then Schiff reagent for $90 \mathrm{~min}$., with appropriate washes between all steps. Squashes were made in $45 \%$ acetic acid with birch and pea tissue particles placed side by side under separate cover slips on one slide. The slides were frozen over a cold plate and the cover slips were removed. The slides were air-dried and were kept dust- and light-protected for a maximum of a few days.

Measurement of DNA content was performed with video-based DNA image densitometry using the CIRES, version 3.1 (Kontron, Munich), using a 63x oil objective (Zeiss),

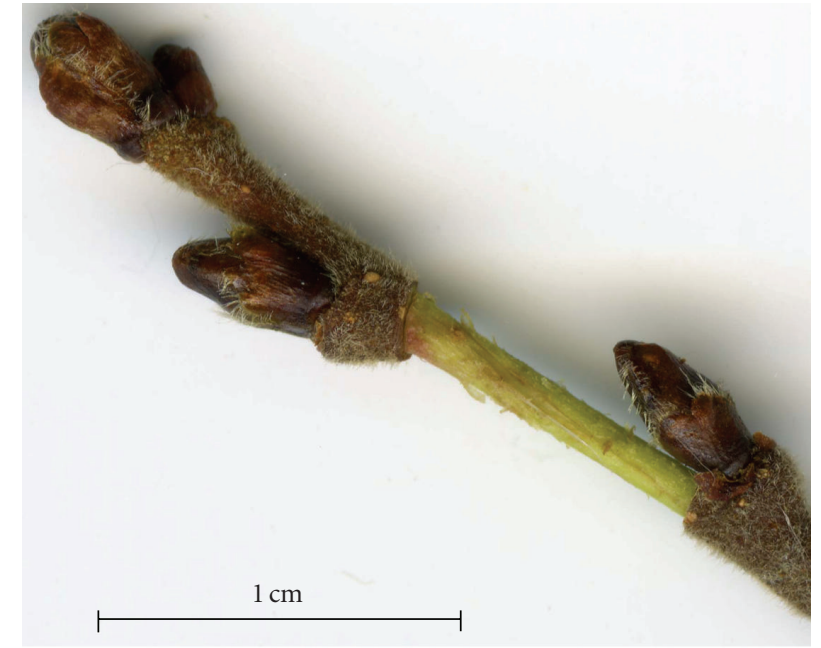

Figure 1: Winter twig of Betula from Bifröst woodland (plant no. 72) — decorticated twig as used for flow cytometry.

green and neutral filters, the green channel of the video camera, and "local" background determination (around each nucleus separately). Three slides per plant were measured except on one occasion where two slides were examined, and usually 100 unreplicated nuclei per slide of birch and pea each were measured for DNA content determination. For each slide the 1C DNA content of birch was calculated using the birch/pea mean 2C DNA content ratio and $4.42 \mathrm{pg}$ (1C) for pea [18]. The $\mathrm{pg} / \mathrm{Mbp}$ conversion factor used is $1 \mathrm{pg}=978 \mathrm{Mbp}$ [19]. Genome sizes are presented as 1Cvalues (holoploid genome size) and $1 \mathrm{CX}$-values (monoploid genome size), as proposed in $[20,21]$. We use the term "DNA ploidy" [22] to indicate that ploidy level was inferred from DNA amounts instead of chromosome counts.

2.4. Genome Size Determination Using Flow Cytometry. In contrast to the Feulgen method using formaldehyde fixation, the FCM approach was shown to be unsuitable for sprouting leaf buds of birch because of an abundant amount of secondary metabolites. Icelandic birch, like the mountain birch of Scandinavia, is known to produce excessive amounts of primary and secondary metabolites in its leaves, especially the herbivory-related phenolic compounds [23]. We therefore looked for different materials for the FCM in this project.

Samples of young, winter-dormant twigs were collected from nine plants in the Bifröst woodland (Table 1) in November 2009. These plants were analysed morphologically and cytogenetically, except the two samples collected at this site from plants having the growth habit of $B$. nana (Bn- 1 and $\mathrm{Bn}-2$ ). Four of the karyotyped plants were analysed by FDM in 2007. The twig samples were sent by airmail to Vienna for the FCM study. The sample preparation for FCM began six days after the samples were collected in the field in Iceland.

About 1-2 cm long pieces of the youngest twig internodes were decorticated (Figure 1) and the cortex discarded, while the remaining twig was kept moist. Using a sharp razor blade, the decorticated twig segments were cochopped [24] 
with Solanum pseudocapsicum leaves (1.29 pg DNA/1C [25] for internal standardization) in Otto's buffer I $[26,27]$. The resulting nuclei isolate was filtered through a $30 \mu \mathrm{m}$ mesh (Saatilene) and treated for $30 \mathrm{~min}$. with RNase-A (0.15 $\mathrm{mg} / \mathrm{mL}$ ) at $37^{\circ} \mathrm{C}$ in a water bath. Thereafter, propidium iodide (PI, final concentration $50 \mu \mathrm{g} / \mathrm{mL}$ ) dissolved in Otto's buffer II [26] was added to stain the nuclei at neutral $\mathrm{pH}$ for at least $1 \mathrm{~h}$ in a refrigerator. Decorticated winter twigs yielded enough nuclei for suitable histograms (Figure 2). Good separation of the $2 \mathrm{C}$ peaks of Betula and Solanum from debris is shown by the SSC versus fluorescence analysis in Figure 2 (insert). Tests for the interference of secondary compounds with nuclei fluorescence were made with chopped birch twigs and standard leaves alone and in combination. The measurements were made at constant instrument settings [27].

Genome size measurements were done using FloMax software on a CyFlow ML flow cytometer (Partec, Münster, Germany) equipped with a green laser $(100 \mathrm{~mW}, 532 \mathrm{~nm}$, Cobolt Samba, Cobolt AB, Stockholm, Sweden). The Cvalues were calculated for every run from the ratio of the mean fluorescence intensities of the standard and the birch G1 peaks. Usually the CV\% of single peaks was lower than $3 \%$ and three runs (5000 particles/run) per preparation were sufficient. If the CV\% was higher (up to maximal 5\%), an additional one or two runs were done. Statistical tests (ANOVA and Wilcoxon pair test) were made using SPSS 10.

\section{Results}

3.1. Ploidy and Morphological Characterization. The plants from Bifröst were characterized morphologically and cytogenetically (Figure 3 ) and were localized onto the quantitative introgression map of this woodland (Figure 4). Of the 42 plants examined, 16 plants (38\%) were confirmed with accurate chromosome counts as being diploid $(2 n=2 \mathrm{x}=$ 28), 23 plants $(55 \%)$ as tetraploid $(2 n=4 \mathrm{x}=56)$, and 3 plants $(7 \%)$ as triploid with 42 chromosomes (see examples in Figures 3(d)-3(f)). The percentages of different ploidy groups within the Bifröst population are similar to those found in all woodlands combined [7]. No aneuploid cells or aneuploid plants were detected. Ten of these plants were used in the genome size study (see Table 1): three diploid Betula nana, two triploid and five tetraploid B. pubescens plants.

The plants from Bifröst woodland represent the overall features of Icelandic birch in general. The plants are mostly morphologically introgressed birch although they are remarkably stable at the ploidy level, that is, the population consists only of diploid, triploid, and tetraploid plants, no aneuploids. But to what extent has Icelandic birch been modified, via introgressive hybridization? Botanically [28] the two Betula species differ mainly in that the dwarf birch species $B$. nana has orbicular or obovate-orbicular sessile leaves which are regularly crenate and are rounded at both leaf tip and base (similar to the leaves in Figure 3(a)), whereas the leaf shape of $B$. pubescens is usually cordate with dentate margins and a distinct petiole (similar to that

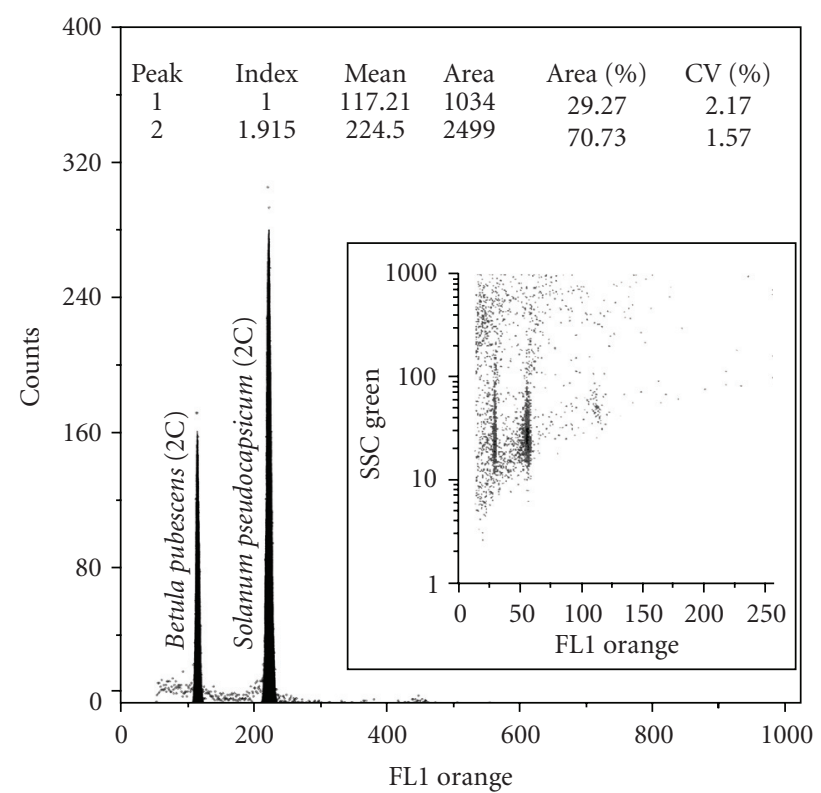

FIgURe 2: Flow histogram of Betula pubescens and the internal standard Solanum pseudocapsicum, with an inset showing scattergram of the side scatter (SSC green) and the fluorescence (FL1 orange) data of the particles measured.

of the tetraploid birch in Figure 3(c)). In the morphology index scale from zero for $B$. nana to 13 for $B$. pubescens (see Materials \& Methods), given null introgression, the Icelandic diploid, triploid, and tetraploid groups from Bifröst were found to have average scores of 1.4 (higher than 0 ), 4.0 (relative intermediate), and 8.4 (much lower than 13), respectively. These are about the same average scores as those obtained from all major birch woodlands in Iceland combined [7]. The bidirectional introgression has clearly brought the two species closer to each other. Apart from these mean values, however, there is a considerable variation within ploidy groups. The diploid B. nana plants from Bifröst, for example, have a morphology index of 2 (Figure 3(a)), but 1 and 3 in the plants used in our genome size study (Table 1). The triploid plant in Figure 3(b) has a morphology index of 4, like the other two triploids examined in this study (Table 1). The tetraploid B. pubescens plant in Figure 3(c) has the typical index of 9 for this species in Icelandic woodlands, whereas those used in the genome size study show 6-10 in their morphology scale (Table 1).

The majority of the plants that were recorded as $B$. nana and $B$. pubescens in the field were found to be diploid and tetraploid, respectively. Triploid individuals, on the other hand, resembled either species as frequently as they appeared as morphological intermediates. But when quantitative species-specific characteristics of leaf shape were analysed, the plants from Bifröst woodland were separated into two groups only, that is, diploid and tetraploid groups (Figure 4). The triploids were not statistically distinguishable from $B$. pubescens. The same analyses applied to triploid plants from woodlands throughout Iceland: the triploids did not form an intermediate group [7]. 


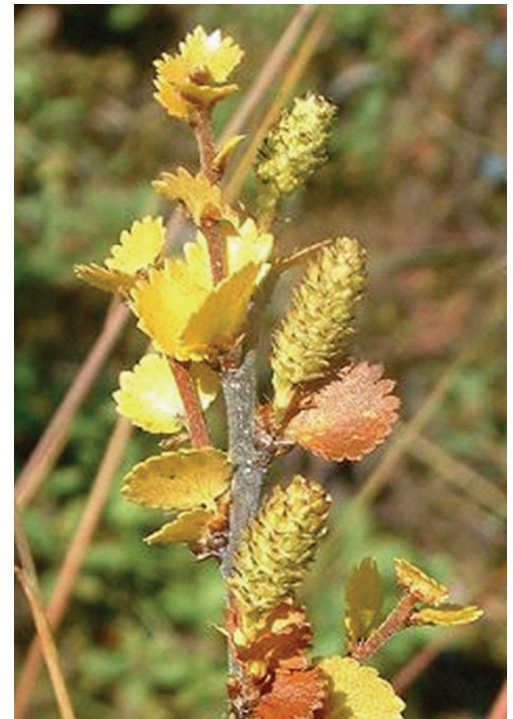

(a)

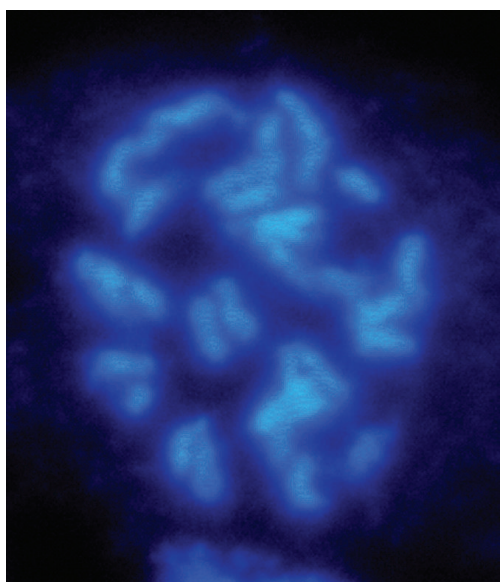

(d)

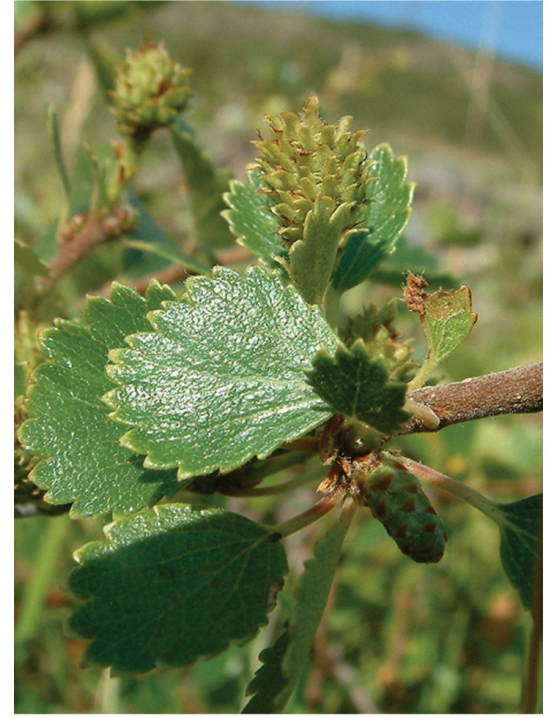

(b)

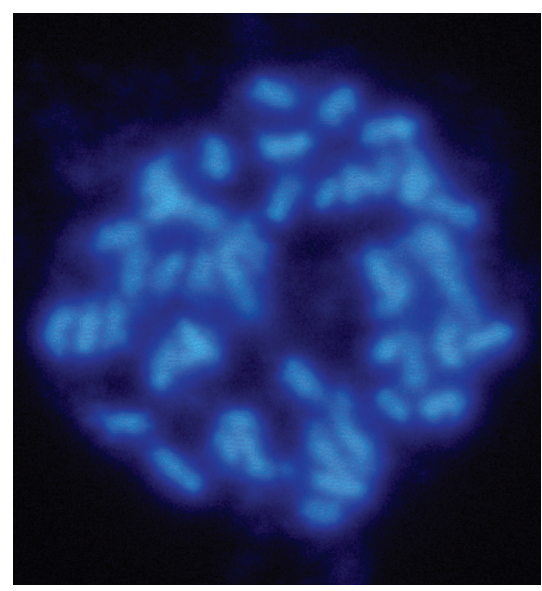

(e)

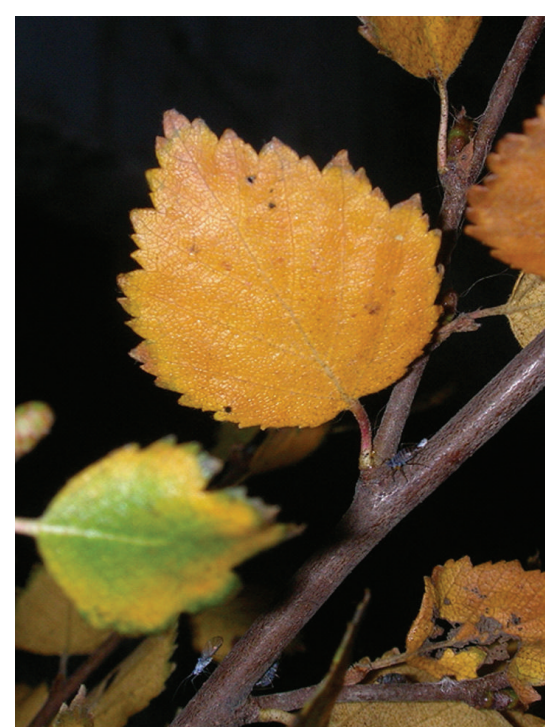

(c)

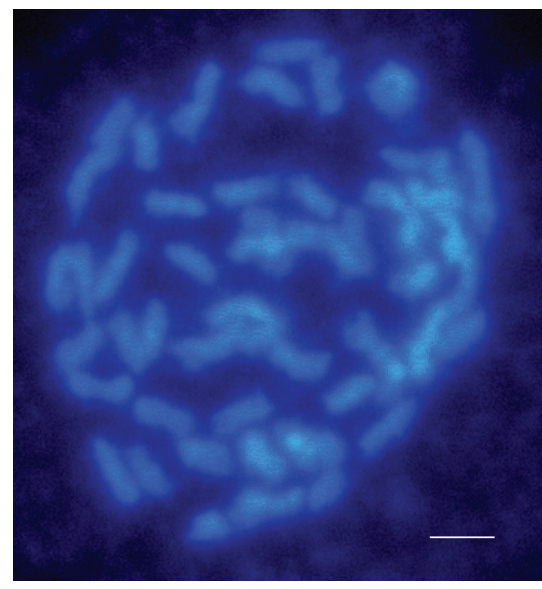

(f)

FIgURe 3: Betula from the woodland Bifröst, western Iceland-the plants and their chromosome numbers: (a) and (d) diploid $B$. nana, $2 n$ $=2 \mathrm{x}=28$, morphology index 2 ; (b) and (e) triploid interspecific hybrid, $2 n=3 \mathrm{x}=42$, morphology index 4 ; and (c) and (f) tetraploid $B$. pubescens, $2 n=4 \mathrm{x}=56$, morphology index 9. The scale bar represents $2 \mu \mathrm{m}$.

\subsection{Genome Size in Icelandic Birch}

3.2.1. Feulgen DNA Image Densitometry (FDM). Formaldehyde fixation and the Feulgen procedure resulted in delicately magenta-stained and often isolated birch nuclei, and a colourless transparent cytoplasm, in which solid bodies of polymerized condensed tannins were abundantly present in many but not all cells (compare with Greilhuber [29]). These tannin bodies were localized within the vacuoles. None or very little mitotic activity was observed in the slides. Mitotic nuclei, if found, conformed to the corresponding interphase 2C and 4C distributions. Somewhat higher CVs within some slides could be attributed to some background granulation. In the cells of the resting pea embryos used as standard, no tannins were found. Their nuclei were nonreplicating and conformed well to ploidy classes. Only 2C nuclei were used for calculation. Within-slide CVs in birch were mostly below
$6 \%$, with one exception of $7 \%$, while in pea they were $1.5 \%$ to $3 \%$.

Of seven birch samples (individual plants), three were "DNA diploid" with 441.4 Mbp on average, one was "DNA triploid" with $670.8 \mathrm{Mbp}$, and three were "DNA tetraploid" with $879.2 \mathrm{Mbp}(1 \mathrm{C}$ ) on average (Tables 1 and 2). The $1 \mathrm{Cx}-$ value was fairly constant between individuals at $441.4 \mathrm{Mbp}$ $(\mathrm{CV}=1.6 \%, n=7$, nonsignificant difference between individuals upon two-sided monofactorial ANOVA, $F_{6,13}$ $=1.09, P=0.418$ ), and the variances were homogeneous (Levene test, $P=0.177)$. Likewise, different ploidy levels did not differ significantly in their $\mathrm{CX}$-values $\left(F_{2,4}=0.340, P=\right.$ $0.730)$.

3.2.2. Flow Cytometry Using Decorticated Twigs. As far as we know, the use of woody plant twigs in FCM for otherwise recalcitrant material is new. The test of interference of 
TABLE 2: Genome sizes of diploid, triploid and tetraploid Icelandic birch: mean 1C-values and average sizes between FDM and FCM.

\begin{tabular}{llccc}
\hline \multirow{2}{*}{ Ploidy group } & & 1C $(\mathrm{Mbp})$ & Average size & Average size in pg (1C) \\
& FDM & FCM & 447.8 & 0.46 \\
Diploid & 441.4 & 457.6 & 666.1 & 0.68 \\
Triploid & 670.8 & 663.8 & 881.8 & 0.90 \\
Tetraploid & 879.2 & 883.9 & \\
\hline
\end{tabular}

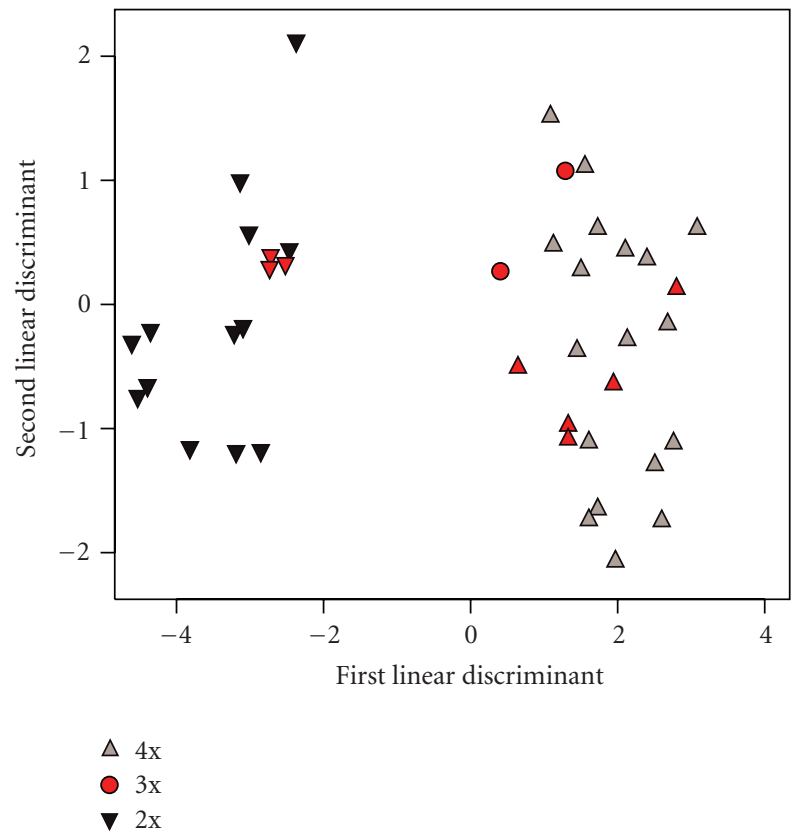

FIGURE 4: Linear discriminant analysis of leaf shape variables in 41 birch plants from Bifröst: 16 diploid, 2 triploid, and 23 tetraploid. Originally there were 3 triploid plants, but one was missing from this data set although the plant was characterized (Figure 3(b)). The labels in red are individuals used in the genome size study, 10 in total. The analysis shows two clusters, diploid and tetraploid. The triploid plants fall within the tetraploid cluster.

phenolics showed unexpectedly somewhat increased fluorescence and improved peak CVs in both birch and standard, if chopped in combination, compared with lone isolates of both. In five tests, the increase in nuclei fluorescence was 1.043-fold in the standard and 1.038-fold in Betula pubescens. This is at present difficult to explain and needs further investigation, but the tests seem to indicate a compensating effect of the joint preparation which justifies the internal standardization.

The results from nine accessions examined clearly disclosed the respective ploidy levels: two were "DNA diploid" with $457.6 \mathrm{Mbp}$ on average, two were "DNA triploid" with $663.8 \mathrm{Mbp}$, and five were "DNA tetraploid" with $883.9 \mathrm{Mbp}$ (1C) on average (Tables 1 and 2). The ploidy status derived from FCM again corresponded unambiguously with the chromosome number obtained cytogenetically. The two samples that had the growth habit of $B$. nana in the field (no leaves in mid-winter for botanical identification) were correctly identified as belonging to the diploid species

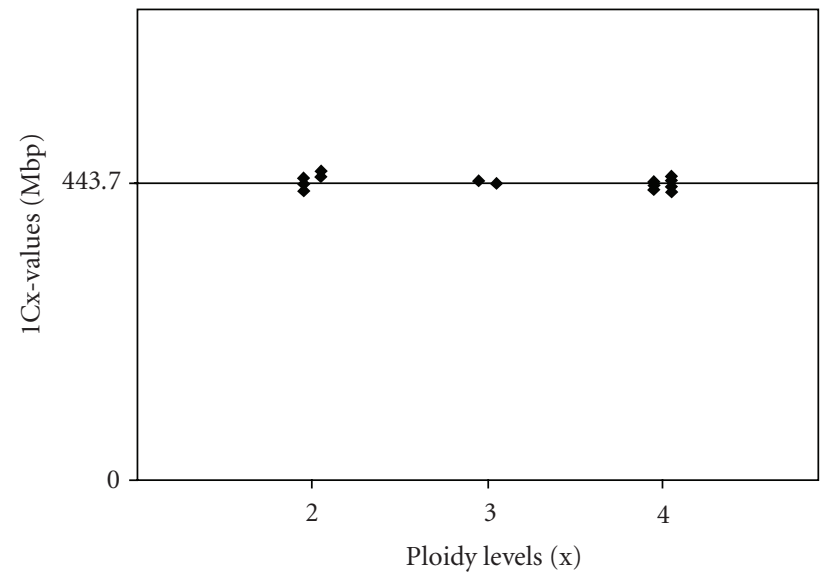

FIGURE 5: Distribution of 1CX-values of birch samples from Bifröst woodland according to ploidy levels and techniques (FDM at left, FCM at right). The horizontal line indicates the grand mean of all measurements (see Table 1).

(Table 1). The Cx-values of these three ploidy levels were also subjected to ANOVA, but the differences were found to be nonsignificant $\left(F_{2,6}=3.048, P=0.122\right)$. However, a weak but real downsizing cannot be rejected and this might be detected in the future using a larger sample size. The mean $\mathrm{Cx}$-value was 0.966 -fold in tetraploids compared with diploids, and the intermediate $\mathrm{Cx}$-value in triploids was very close to the theoretical expectation.

\subsubsection{Flow Cytometry Compared with Feulgen Densitometry.} From the four individuals (one triploid and three tetraploid) measured using both techniques (FDM and FCM), no technique-dependent trend in C-values can be deduced (Table 3). The nonparametric Wilcoxon test for paired samples revealed a two-sided error significance of 0.715 , and so both methods yielded equivalent results. All FCM-derived $\mathrm{CX}$-values compared with FDM-derived ones showed that the individuals in both groups were not statistically different $\left(\mathrm{df}_{1,14} F=0.894, P=0.360\right)$. The $\mathrm{Cx}$-values of the three ploidy levels obtained with either method (i.e., all $2 x, 3 x$, and $4 x$ data compared $)$ were also not different $\left(\mathrm{df}_{2,13} F=0.966\right.$, $P=0.406$ ). The overall mean $1 \mathrm{Cx}$-value from all three ploidy groups is $444 \mathrm{Mbp}$ (Figure 5).

In summary, based on the average 1C-values obtained, the $1 \mathrm{C}$ genomes of diploid Betula nana, triploid interspecific hybrid and tetraploid B. pubescens were found to be 448, 666 and $882 \mathrm{Mbp}$ DNA, respectively (Table 2). The mean Cvalue of the tetraploid species $B$. pubescens was therefore very 
TABLE 3: Comparison of 1CX-values (Mbp) obtained with FCM and FDM methods.

\begin{tabular}{lccc}
\hline Plant no. & 1Cx $($ FCM $)$ & 1Cx $($ FDM $)$ & Ratio FCM/FDM \\
\hline $81(3 x)$ & 447.2 & 441.7 & 1.012 \\
$71(4 x)$ & 445.4 & 439.3 & 1.014 \\
$83(4 x)$ & 433.7 & 453.5 & 0.956 \\
$92(4 x)$ & 439.7 & 438.4 & 1.003 \\
Means $4 x$ & 439.6 & 443.7 & 0.991 \\
\hline
\end{tabular}

close to being twice (1.97-fold) that of the diploid species $B$. nana (Table 2). The mean C-value of the triploid hybrids was intermediate between the two species, very close to the theoretical expectation. The morphological assessment of these plants, on the other hand, did not reveal a linear relationship among the three ploidy groups (Table 1, Figure 4).

\section{Discussion}

Genome sizes of Icelandic birch obtained in this study correlate perfectly with the ploidy level-the average 1C genome size of the tetraploid Betula pubescens ( $882 \mathrm{Mbp}$ ) is about twice the size of the genome of the diploid species $B$. nana (448 Mbp), and the triploid group has the average size of $666 \mathrm{Mbp}$, which is mid-way between the two species.

The discovery that the triploid hybrid genome is intermediate in its size has a great biological significance. Firstly, it confirms that the triploids are interspecific hybrids of these two coexisting birch species, most probably containing a complete genome from each parental species. Chromosomal mapping in Icelandic birch using the $18 \mathrm{~S}-25 \mathrm{~S}$ ribosomal markers $[1,30]$ has also shown that the triploid genome is a hybrid containing one set of chromosomes from each parental species. The triploid genome has five nonhomologous 18S-25S rDNA sites, two from B. nana and three from $B$. pubescens [1]. Secondly, the present study indicates that triploid birch in Iceland is probably of recent origin. As the genome size of the triploid group is an almost exact intermediate between the currently introgressed parental species, it must have been formed through recent hybridization. Our palynological study [31] has indeed shown that hybridization in Icelandic birch occurred after the first colonization of birch species in Iceland in the early Holocene and has been going on ever since. Thirdly, there seems to be no major genome/chromosome rearrangements accompanying the interspecific hybridization that could have resulted in significant deviation from the intermediate hybrid genome size observed in the present study. Although we need to measure genome size in a much larger sample size, these first results are statistically significant and hence meaningful. It is impressive that even in the face of extensive gene flow, based on morphological assessment, genome size has proven to be a stable character. There must have been some form of selection pressure that has maintained the species integrity despite introgression. Some elements in the arctic and subarctic environments may have a role in maintaining the genomic stability, by for example, selecting against aneuploidy.
Genome downsizing cannot be statistically proven in the polyploid genomes of these plants. This could be considered a rare situation given that genome downsizing is common in angiosperms [9], whereby polyploids are expected to have proportional larger $\mathrm{C}$-values than their diploid progenitors. The present study shows $1.97 \mathrm{x}$ increase in genome size on average, from diploid to tetraploid levels, whereas the analysis of observed genome size changes in angiosperms [9] reveals at the most $1.2 \mathrm{x}$ increase for eudicots. The average $\mathrm{CX}$-values among different ploidies in the present study are also constant statistically. The reason for not seeing genome downsizing in our study could be that the diploid species $B$. nana is probably not the diploid progenitor of the tetraploid $B$. pubescens. The two species are taxonomically and geographically differentiated in a broad sense. In geographically overlapping zones, such as Iceland, the two species hybridize but this secondary contact does not give rise to a new species. Taxonomically, $B$. nana belongs to the subsection Nanae, whereas $B$. pubescens belongs to the subsection Albae with the other European tree birch species B. pendula $[28,32]$. The ribosomal mapping on chromosomes of $B$. nana and B. pubescens [30] supports the two species having different genome origins. The phylogenetic studies using the nuclear $\mathrm{ADH}$ gene and DNA sequences of the chloroplast matK gene [33] as well as AFLP markers [34] indicate that the tetraploid species $B$. pubescens has a hybrid origin, that is, is an allopolyploid. However, no conclusive evidence has been found as to the identity of its diploid progenitors. Until the hybrid genomes of the tetraploid species $B$. pubescens have been correctly identified, it is not possible to test if genome downsizing has actually occurred in Betula.

The Plant DNA C-values Database [35] reports 1Cvalues of only two Betula species, an eastern N-American tree birch species B. populifolia with $0.2 \mathrm{pg}$ [36] and B. pubescens (European tree birch species examined in the present study) with $0.75 \mathrm{pg}$ [37], previously given as $0.7 \mathrm{pg}$ [38]. Both species were measured using Feulgen densitometry after acetic alcohol fixation, without chromosome counts reported. For both species, a diploid chromosome number $2 n=28$ is given in the C-values Database. However, all chromosome counts for $B$. pubescens according to Index to Plant Chromosome Numbers (IPCN, on 16 October 2009, http://mobot.mobot.org/W3T/Search/ipcn.html) and many earlier sources report the tetraploid number $2 n=56$. Apart from this, the differing 1C-values of 0.7 or $0.75 \mathrm{pg}$ for $B$. pubescens [37, 38, resp.,] come from using a recalibrated standard value of Senecio vulgaris in Mowforth's thesis [37] (compare Bennett and Smith $[39,40]$ and see footnotes $b$ 
and $i$ in the latter). Assuming that the values from $[37,38]$ actually refer to $B$. pubescens with $2 n=56$, their $1 C$-value of $0.7 \mathrm{pg}$ or $0.75 \mathrm{pg}$ is 0.78 - to 0.83 -fold the present $1 \mathrm{C}$-value of $0.902 \mathrm{pg}$ for the tetraploid level. Both these lower Feulgen values are however compatible with our data, if possible tannin interference in their samples, which one could expect in birch after acetic alcohol fixation (see Greilhuber [29]) is assumed. The 1C-value of $0.2 \mathrm{pg}$ for B. populifolia [36] appears too low for a diploid birch.

The congruence of FDM- with FCM-values in the present study and their unbiased correlation with ploidy levels agrees with the visual aspect of good, regularly stained formaldehyde-fixed Feulgen-stained nuclei, even though ample solidified tannins were present in many cells of the bud tissues. FDM is clearly a valid method for the purpose. Regarding FCM, the suitability of the chopping method for young decorticated and, in our case, dormant twigs is a useful addition to the flow cytometric practice. First of all, twigs of trees are, it seems, an organ of woody plants that are always available but hitherto never or rarely employed (see Supplemental Appendix in [41]). It is worth noting that in some cases stems of shrubby Fabaceae were used instead of leaves to improve histogram quality [42]. Secondly, this approach extends the application to the cold season, when leaves are not available and buds may be unsuitable because of secondary compounds such as resins. In birch, twig tissue has, in contrast to buds, no disturbing resins. The use of young and even dormant twigs for genome size measurement as reported in this study should be applicable for studying a broad range of tree species.

\section{Acknowledgment}

The authors thank I. J. Leitch for communicating details on methods used for Feulgen DNA measurement in Betula pubescens from the thesis of M. A. G. Mowforth.

\section{References}

[1] K. Anamthawat-Jónsson and Æ. Th. Thórsson, "Natural hybridisation in birch: triploid hybrids between Betula nana and B. pubescens," Plant Cell, Tissue and Organ Culture, vol. 75, no. 2, pp. 99-107, 2003.

[2] W. J. De Groot, P. A. Thomas, and R. W. Wein, "Betula nana L. and Betula glandulosa Michx," Journal of Ecology, vol. 85, no. 2, pp. 241-264, 1997.

[3] M. D. Atkinson, "Biological flora of the British Isles: Betula pendula Roth (B. verrucosa Ehrh.) and B. pubescens Ehrh.," Journal of Ecology, vol. 80, no. 4, pp. 837-870, 1992.

[4] T. H. Jónsson, "Stature of sub-arctic birch in relation to growth rate, lifespan and tree form," Annals of Botany, vol. 94, no. 5, pp. 753-762, 2004.

[5] T. T. Elkington, "Introgressive hybridization between Betula nana L. and B. pubescens Ehrh. in North-West Iceland," New Phytologist, vol. 67, pp. 109-118, 1968.

[6] K. Anamthawat-Jónsson and T. Tómasson, "Cytogenetics of hybrid introgression in Icelandic birch," Hereditas, vol. 112, no. 1, pp. 65-70, 1990.

[7] Æ. Th. Thórsson, S. Pálsson, A. Sigurgeirsson, and K. Anamthawat-Jónsson, "Morphological variation among Betula nana (diploid), B. pubescens (tetraploid) and their triploid hybrids in Iceland," Annals of Botany, vol. 99, no. 6, pp. 1183-1193, 2007.

[8] Æ. Th. Thórsson, E. Salmela, and K. Anamthawat-Jónsson, "Morphological, cytogenetic, and molecular evidence for introgressive hybridization in birch," Journal of Heredity, vol. 92, no. 5, pp. 404-408, 2001.

[9] I. J. Leitch and M. D. Bennett, "Genome downsizing in polyploid plants," Biological Journal of the Linnean Society, vol. 82, no. 4, pp. 651-663, 2004.

[10] J. L. Bennetzen and E. A. Kellogg, "Do plants have a one-way ticket to genome obesity?" Plant Cell, vol. 9, pp. 1509-1514, 1997.

[11] J. S. Hawkins, S. R. Proulx, R. A. Rapp, and J. F. Wendel, "Rapid DNA loss as a counterbalance to genome expansion through retrotransposon proliferation in plants," Proceedings of the National Academy of Sciences of the United States of America, vol. 106, no. 42, pp. 17811-17816, 2009.

[12] P. Nosil, D. J. Funk, and D. Ortiz-Barrientos, "Divergent selection and heterogeneous genomic divergence," Molecular Ecology, vol. 18, no. 3, pp. 375-402, 2009.

[13] A. C. Brennan, J. R. Bridle, A.-L. Wang, S. J. Hiscock, and R. J. Abbott, "Adaptation and selection in the Senecio (Asteraceae) hybrid zone on Mount Etna, Sicily," New Phytologist, vol. 183, no. 3, pp. 702-717, 2009.

[14] Æ. Th. Thórsson, S. Pálsson, M. Lascoux, and K. AnamthawatJónsson, "Introgression and phylogeography of Betula nana (diploid), B. pubescens (tetraploid) and their triploid hybrids in Iceland inferred from cp-DNA haplotype variation," Journal of Biogeography. In press.

[15] G. P. Quinn and M. J. Keough, Experimental Design and Data Analysis for Biologists, Cambridge University Press, Cambridge, UK, 2002.

[16] K. Anamthawat-Jónsson, "Preparation of chromosomes from plant leaf meristems for karyotype analysis and in situ hybridization," Methods in Cell Science, vol. 25, no. 3-4, pp. 91-95, 2004.

[17] J. Greilhuber and E. M. Temsch, "Feulgen densitometry: some observations relevant to best practice in quantitative nuclear DNA content determination," Acta Botanica Croatica, vol. 60, no. 2, pp. 285-298, 2001.

[18] J. Greilhuber and I. Ebert, "Genome size variation in Pisum sativum," Genome, vol. 37, no. 4, pp. 646-655, 1994.

[19] J. Doležel, J. Bartoš, H. Voglmayr, and J. Greilhuber, "Nuclear DNA content and genome size of trout and human," Cytome$\operatorname{try} A$, vol. 51, no. 2, pp. 127-128, 2003.

[20] J. Greilhuber, J. Doležel, M. A. Lysák, and M. D. Bennett, "The origin, evolution and proposed stabilization of the terms 'genome size' and 'C-value' to describe nuclear DNA contents," Annals of Botany, vol. 95, no. 1, pp. 255-260, 2005.

[21] J. Greilhuber and J. Doležel, "2C or not 2C: a closer look at cell nuclei and their DNA content," Chromosoma, vol. 118, pp. 391-400, 2009.

[22] J. Suda, A. Krahulcová, P. Trávnícek, and F. Krahulec, "Ploidy level versus DNA ploidy level: an appeal for consistent terminology," Taxon, vol. 55, no. 2, pp. 447-450, 2006.

[23] S. Haviola, I. Saloniemi, V. Ossipov, and E. Haukioja, "Additive genetic variation of secondary and primary metabolites in mountain birch," Oikos, vol. 112, no. 2, pp. 382-391, 2006.

[24] D. W. Galbraith, K. R. Harkins, J. M. Maddox, N. M. Ayres, D. P. Sharma, and E. Firoozabady, "Rapid flow cytometric analysis of the cell cycle in intact plant tissues," Science, vol. 220, no. 4601, pp. 1049-1051, 1983.

[25] E. M. Temsch, J. Greilhuber, and R. Krisai, "Genome size in liverworts," Preslia, vol. 82, pp. 63-80, 2010. 
[26] F. J. Otto, H. Oldiges, W. Göhde, and V. K. Jain, "Flow cytometric measurement of nuclear DNA content variations as a potential in vivo mutagenicity test," Cytometry, vol. 2, no. 3, pp. 189-191, 1981.

[27] J. Greilhuber, E. M. Temsch, and J. Loureiro, "Nuclear DNA content measurement," in Flow Cytometry with Plant Cells: Analysis of Genes, Chromosomes, and Genomes, J. Doležel, J. Greilhuber, and J. Suda, Eds., pp. 67-101, Wiley-VCH, Weinheim, Germany, 2007.

[28] S. M. Walters, "Betulaceae," in Flora Europaea, Vol. 1, T. G. Tutin, V. H. Heywood, N. A. Burges, D. H. Valentine, S. M. Walters, and D. A. Webb, Eds., pp. 57-59, Cambridge University Press, Cambridge, UK, 1964.

[29] J. Greilhuber, "Cytochemistry and C-values: the less-wellknown world of nuclear DNA amounts," Annals of Botany, vol. 101, no. 6, pp. 791-804, 2008.

[30] K. Anamthawat-Jónsson and J. S. Heslop-Harrison, "Molecular cytogenetics of Icelandic birch species: physical mapping by in situ hybridization and rDNA polymorphism," Canadian Journal of Forest Research, vol. 25, no. 1, pp. 101-108, 1995.

[31] L. Karlsdóttir, M. Hallsdóttir, Æ. Th. Thórsson, and K. Anamthawat-Jónsson, "Evidence of hybridisation between Betula pubescens and B. nana in Iceland during the early Holocene," Review of Palaeobotany and Palynology, vol. 156, no. 3-4, pp. 350-357, 2009.

[32] J. J. Furlow, "Betulaceae Gray. Birch family," in Flora of North America, North of Mexico, Vol. 3, Flora of North America Committee, Ed., pp. 507-538, Oxford University Press, New York, NY, USA, 1997.

[33] P. Järvinen, A. Palmé, L. O. Morales et al., "Phylogenetic relationships of Betula species (Betulaceae) based on nuclear $\mathrm{ADH}$ and chloroplast matK sequences," American Journal of Botany, vol. 91, no. 11, pp. 1834-1845, 2004.

[34] M. F. Schenk, C.-N. Thienpont, W. J. M. Koopman, L. J. W. J. Gilissen, and M. J. M. Smulders, "Phylogenetic relationships in Betula (Betulaceae) based on AFLP markers," Tree Genetics and Genomes, vol. 4, no. 4, pp. 911-924, 2008.

[35] M. D. Bennett and I. J. Leitch, "Plant DNA C-values database (release 4.0, October 2005)," http://data.kew.org/cvalues/.

[36] M. J. Olszewska and R. Osiecka, "The relationship between 2C DNA content, systematic position, and the level of nuclear DNA endoreplication during differentiation of root parenchyma in some dicotyledonous shrubs and trees. Comparison with herbaceous species," Biochemie und Physiologie der Pflanzen, vol. 179, pp. 641-657, 1984.

[37] M. A. G. Mowforth, Variation in nuclear DNA amounts in flowering plants: an ecological analysis, Ph.D. thesis, University of Sheffield, Sheffield, UK, 1985.

[38] J. P. Grime and M. A. Mowforth, "Variation in genome sizean ecological interpretation," Nature, vol. 299, no. 5879, pp. 151-153, 1982.

[39] M. D. Bennett and J. B. Smith, "Nuclear DNA amounts in angiosperms," Philosophical Transactions of the Royal Society of London, vol. 274, no. 933, pp. 227-274, 1976.

[40] M. D. Bennett and J. B. Smith, "Nuclear DNA amounts in angiosperms," Philosophical Transactions of the Royal Society of London, vol. 334, pp. 309-345, 1991.

[41] P. Kron, J. Suda, and B. C. Husband, "Applications of flow cytometry to evolutionary and population biology," Annual Review of Ecology, Evolution, and Systematics, vol. 38, pp. 847876, 2007.
[42] J. Suda, T. Kyncl, and V. Jarolímová, “Genome size variation in Macaronesian angiosperms: forty percent of the Canarian endemic flora completed," Plant Systematics and Evolution, vol. 252, no. 3-4, pp. 215-238, 2005. 

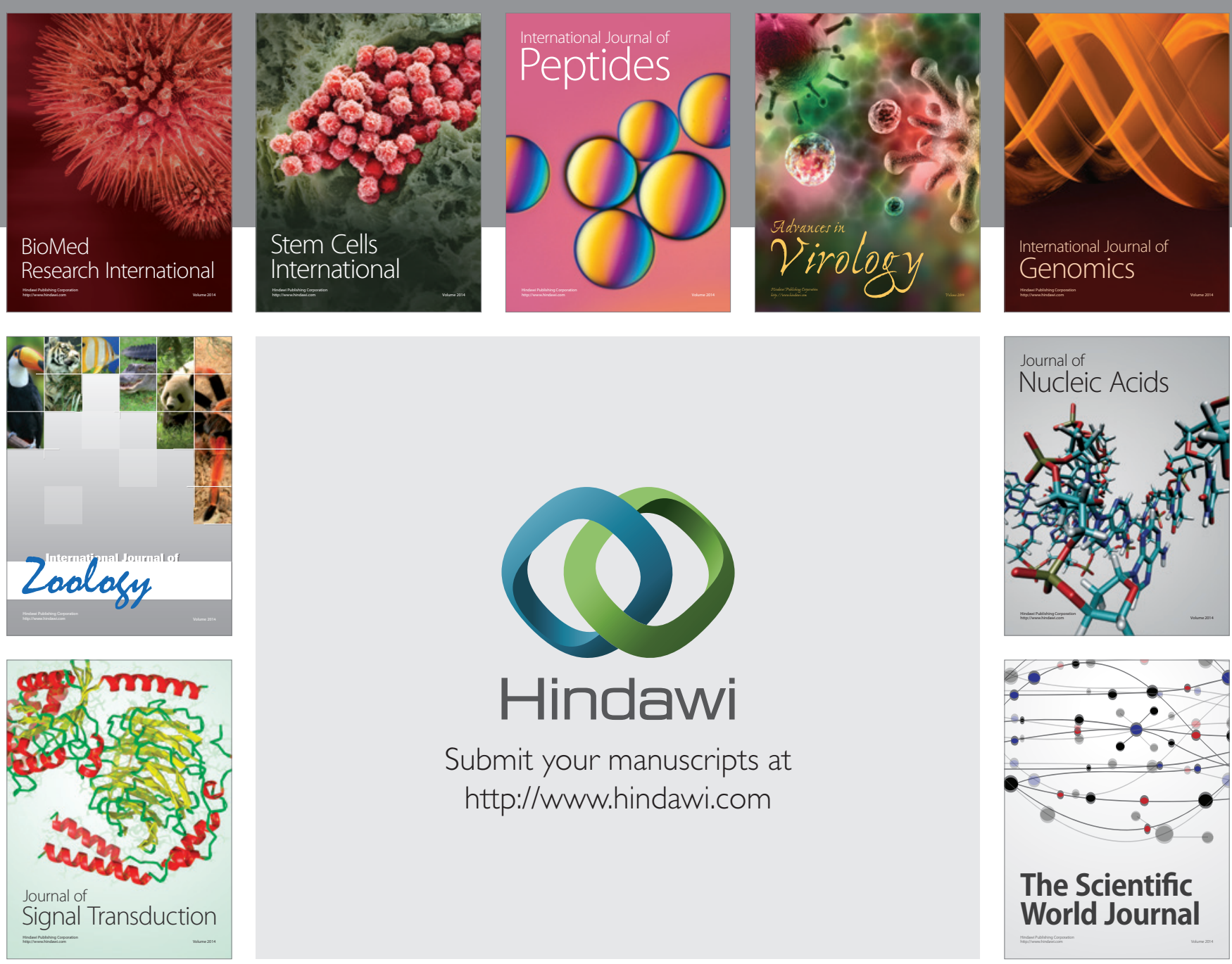

Submit your manuscripts at

http://www.hindawi.com
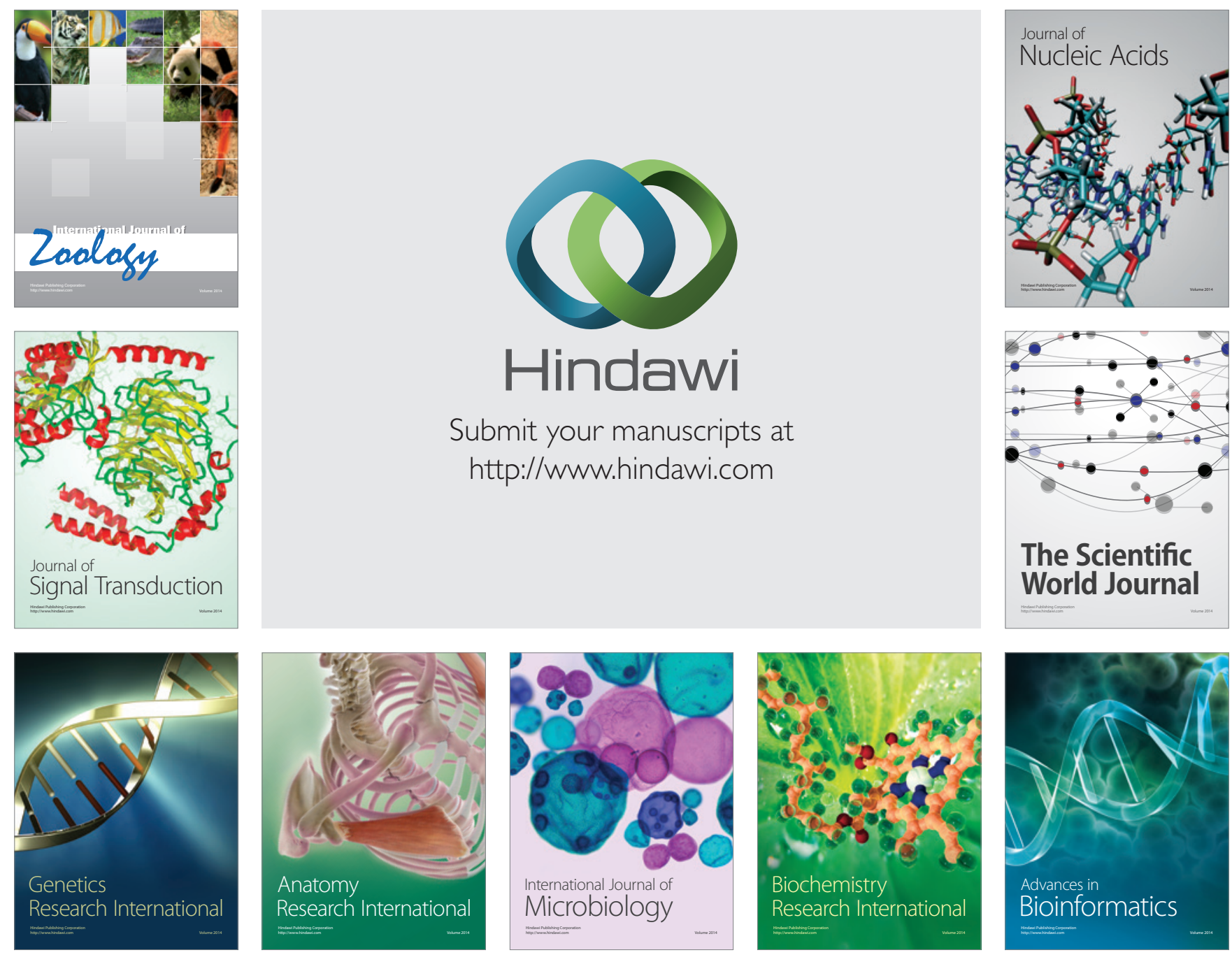

The Scientific World Journal
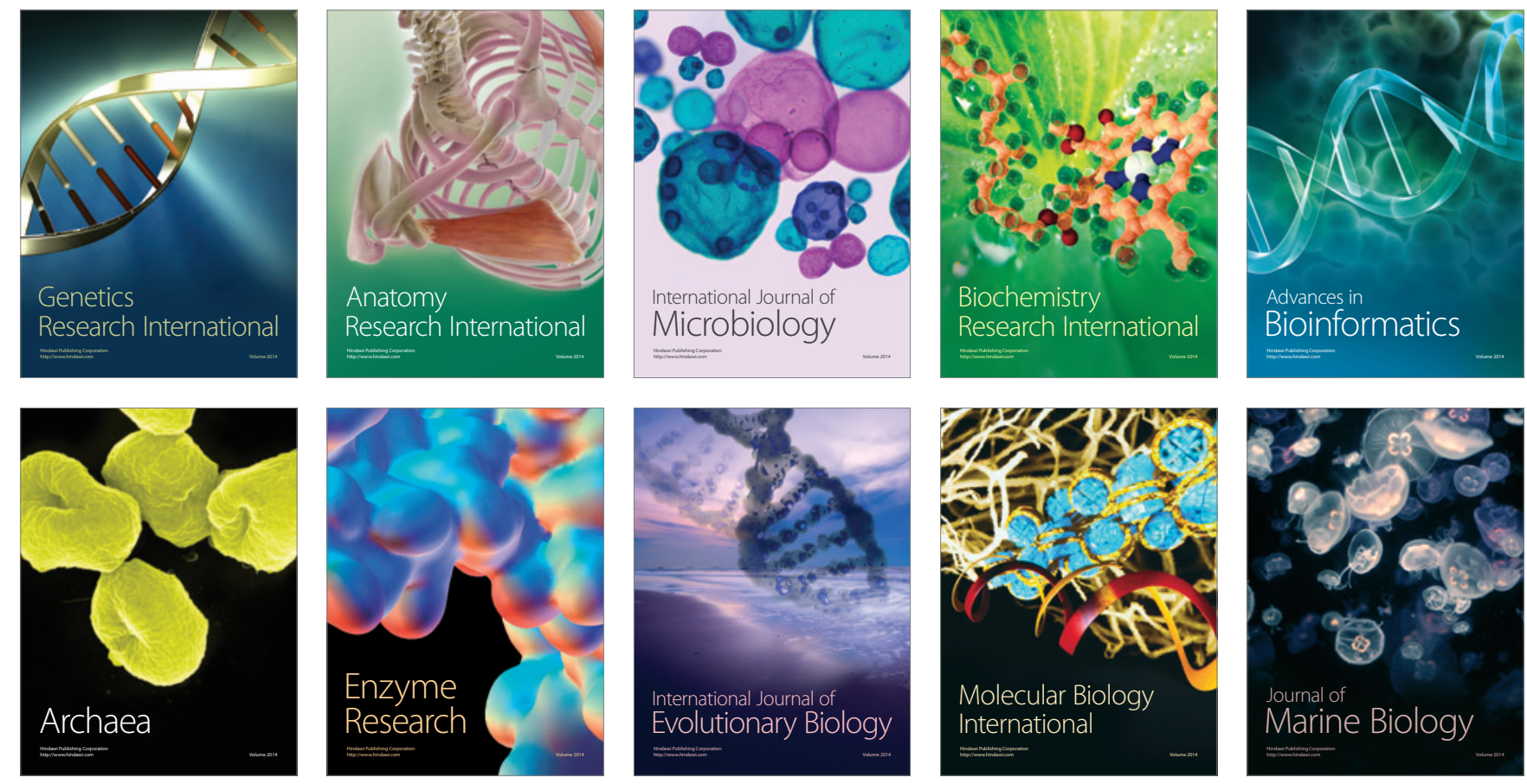